\title{
Drug resistance in relation to use of silver sulphadiazine cream in a burns unit
}

\author{
KIM BRIDGES AND E. J. L. LOWBURY \\ From the MRC Industrial Injuries and Burns Unit, Birmingham Accident Hospital
}

SUMMARY Topical chemoprophylaxis of extensive burns with silver sulphadiazine cream led to large increase in the proportion of sulphadiazine-resistant Gram-negative bacilli in a burns unit When all sulphonamide treatment in the ward was stopped, the incidence of sulphonamide-resistan $\bar{Q}$ strains fell back to levels similar to those recorded when silver sulphadiazine treatment was intro $\omega_{0}$ duced. This was associated with a large reduction in the incidence of resistance of certain Gramis negative bacilli (especially Klebsiella $\mathrm{sp}$ ) to several antibiotics.

Transferable resistance to sulphadiazine, shown by conjugation experiments with Escherichia co $\mathrm{K} 12$, was found in a majority of the strains of Klebsiella sp tested, and in some other species. pattern of transferable resistance to tetracycline, cephaloridine, chloramphenicol, ampicillin, carbenicillin, and sulphadiazine ( $\mathrm{T} \mathrm{Ce} \mathrm{Cl} \mathrm{A} \mathrm{Ca} \mathrm{S}$ ) was found in four of the 22 strains of Klebsiell\& tested, and closely related patterns were transferred by five other strains. These patterns of resistanco were commonly found in Klebsiella sp isolated from burns in the period before the withdrawal of sulphonamides from the ward but were found in none of the Klebsiella strains isolated in the firs six months after that period. Strains of Acinetobacter and Proteus, in which transferable resistafice was not found, showed no appreciable fall or rise in sulphadiazine resistance; there was no falki

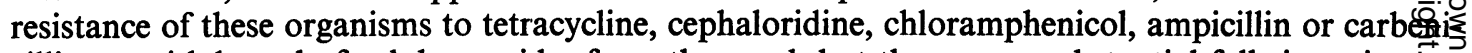
cillin on withdrawal of sulphonamides from the ward, but there were substantial falls in resistance of Acinetobacter to kanamycin, gentamicin, trimethoprim, and tetracycline which were probabl若 not caused by the withdrawal of sulphonamides.

Topical chemoprophylaxis is shown to have great value in the protection of severely burned patients against infection. An important requirement for routine prophylactic applications is stable sensitivity of the main pathogens to the agents applied. Most antibiotics fail in this respect, but polymyxin and certain antiseptics, notably silver nitrate and chlorhexidine, have been used in burns units without evidence of any significant emergence of resistance (Jackson et al., 1951; Cason and Lowbury, 1960; Cason et al., 1966). Silver sulphadiazine cream has been widely used, and though resistance to sulphonamides seemed likely to emerge if this agent was used for routine prophylaxis, this was not reported in various trials of silver sulphadiazine cream (Fox et al., 1969; Stanford et al., 1969; Hummel et al., 1970), including our own trials on smaller burns (Lowbury et al., 1971a and b). However, a recent trial of silver sulphadiazine cream in extensively

Received for publication 15 June 1976 burned patients, which showed it to havesome prophy lactic advantages over $0.5 \%$ silver nitrate compresses. also showed that a large proportion of the Enteros bacteriaceae in burns became highly resistant to sulphadiazine during the trial; this was associated with a reduced prophylactic effectiveness of silvep sulphadiazine cream (Lowbury et al., 1976).

In this paper we describe the changes in sensitivit? patterns of Enterobacteriaceae to sulphadiazine and other antimicrobial agents before and after with drawal of silver sulphadiazine cream, the sulphonv amides, and co-trimoxazole from use in the Burns Unit.

\section{Resistance of Enterobacteriaceae from burns to} sulphonamides and other antimicrobial agents

MATERIAL AND METHODS

Gram-negative bacilli were isolated from burns as described elsewhere (Lowbury et al., 1976). One strain of every colony type isolated per patient peip 


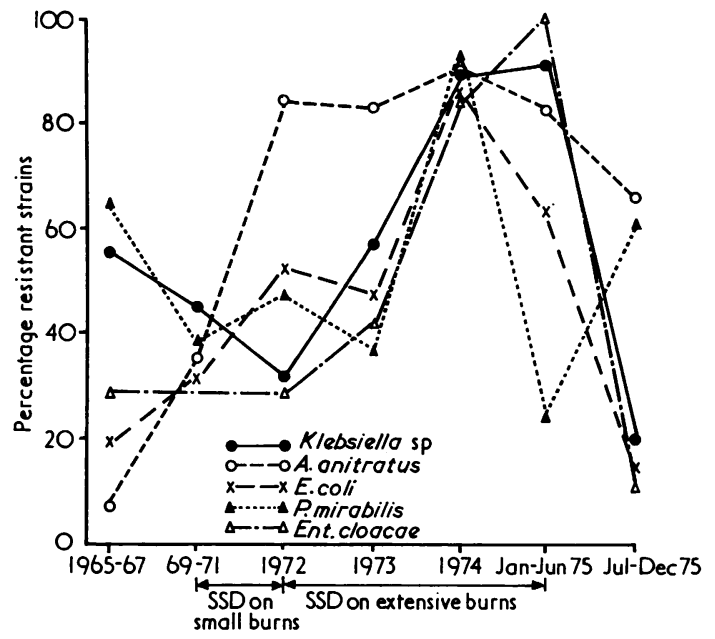

Figure Percentage of strains of certain Gram-negative bacilli isolated from burns between 1965 and 1975 which were resistant to sulphadiazine. The periods in which silver sulphadiazine (SSD) was used and after which all sulphonamides were withdrawn are shown.

month (or, in Jan-June 1974, per fortnight) was picked, identified by standard methods (Cowan and Steel, 1965), and tested for sensitivity to sulphadiazine, trimethoprim, and a range of antibiotics (see below) by a ditch plate technique (Topley et al., 1951). The medium used for tests of sensitivity to sulphadiazine and trimethoprim was $4 \%$ Oxoid Diagnostic Sensitivity Test Agar containing lysed blood. Horse blood agar containing 4\% New Zealand Agar was used for testing the nine other agents. Antibiotics and other antimicrobials were added to the agar medium, which was poured, after mixing, into ditches cut out from opposite sides of the agar plates. The following concentrations ( $\mu \mathrm{g}$ per $\mathrm{ml}$ ) of antibiotics were used: ampicillin, 125; carbenicillin, 100; sulphadiazine, 100; cephaloridine, chloramphenicol, gentamicin, kanamycin, nalidixic acid, tetracycline, and streptomycin, 50; trimethoprim, 10. These concentrations had been selected on the basis of tests previously made in parallel with tube or plate dilution tests; concentrations were chosen which allowed strains shown to be resistant by the dilution tests to grow up to or across the antibiotic ditch. A sensitive control strain of Escherichia coli was inoculated on each ditch plate. A selection of sulphadiazine-resistant strains was tested for minimal inhibitory concentration of sulphadiazine by a plate dilution test.

The Figure shows the proportion of strains isolated from burns of five species of Gram-negative bacilli that were resistant to sulphadiazine during a period covering three trials of silver sulphadiazine and a subsequent period of six months when silver sulphadiazine or sulphonamides were not used. These drugs were withdrawn because of the emergence of a very high incidence of sulphonamideresistant Enterobacteria during the trial of silver sulphadiazine on extensive burns (Lowbury et al., 1976).

The withdrawal of sulphonamides was associated with a prompt and, in the case of Klebsiella sp, $E$. coli, and Enterobacter cloacae, very large reduction in the proportions of sulphonamide-resistant strains; Proteus mirabilis, by contrast, showed an increase in sulphadiazine resistance at the same time. The reversion to previous levels of sulphonamide sensitivity may have been accelerated by the closure of the burn wards for approximately two weeks after the isolation of Salmonella typhimurium from the faeces of a patient with diarrhoea.

Tables 1, 2, 3 and 4 show the proportions of Klebsiella sp, miscellaneous Enterobacteriaceae (E. coli, Enterobacter sp, etc), Acinetobacter anitratus, and Proteus sp from burns which were resistant to each of the 11 antimicrobial drugs on which tests were done during the years 1974 and 1975. Treatment with silver sulphadiazine cream and sulphonamides was stopped in June 1975 because of the high incidence of sulphonamide resistance in the Burns Unit. There was a fall in the proportions of Klebsiella resistant to trimethoprim, kanamycin, streptomycin, and gentamicin in the first half of 1975 (before withdrawal of sulphonamides), and in the second half of 1975 there was a fall in the numbers of strains resistant to sulphadiazine, tetracycline, ampicillin, cephaloridine, chloramphenicol, and

Table 1 Percentage of strains of Klebsiella spp resistant to antimicrobial drugs, 1974 and $1975^{1}$

\begin{tabular}{|c|c|c|c|c|}
\hline \multirow[t]{3}{*}{ Antimicrobial drug } & \multicolumn{4}{|c|}{ Percent of resistant strains in: } \\
\hline & \multicolumn{2}{|l|}{1974} & \multicolumn{2}{|l|}{1975} \\
\hline & Jan-Jun & $J u l-D e c$ & Jan-Jun & Jul-Dec \\
\hline $\begin{array}{l}\text { Sulphadiazine } \\
\text { Trimethoprim } \\
\text { Kanamycin } \\
\text { Streptomycin } \\
\text { Gentamicin } \\
\text { Tetracycline } \\
\text { Ampicillin } \\
\text { Cephaloridine } \\
\text { Carbenicillin } \\
\text { Chloramphenicol } \\
\text { Nalidixic acid }\end{array}$ & $\begin{array}{l}94 \\
35 \\
17 \\
35 \\
8 \cdot 5 \\
90 \\
89 \\
63 \\
86 \\
84 \cdot 5 \\
32\end{array}$ & $\begin{array}{l}88 \\
26 \cdot 5 \\
32 \\
26 \\
18 \\
94 \\
68 \\
59 \\
71 \\
53 \\
29\end{array}$ & $\begin{array}{l}92 \\
4 \\
4 \\
8 \\
4 \\
96 \\
87 \cdot 5 \\
87 \cdot 5 \\
87 \cdot 5 \\
87 \cdot 5 \\
17\end{array}$ & $\begin{array}{r}20 \\
0 \\
0 \\
0 \\
0 \\
20 \\
20 \\
33 \\
33 \\
0 \\
0\end{array}$ \\
\hline Total strains & 71 & 34 & 24 & 15 \\
\hline
\end{tabular}

'Sulphonamides were not used in the Burns Unit after June 1975 
Table 2 Percentage of strains of miscellaneous Enterobacteria resistant to antimicrobial drugs (1974-75)

\begin{tabular}{|c|c|c|c|c|}
\hline \multirow[t]{3}{*}{ Antimicrobial drug } & \multicolumn{4}{|c|}{ Percentage of resistant strains in: } \\
\hline & \multicolumn{2}{|l|}{1974} & \multicolumn{2}{|l|}{1975} \\
\hline & Jan-Jun & $J u l-D e c$ & Jan-Jun & Jul-Dec \\
\hline $\begin{array}{l}\text { Sulphadiazine } \\
\text { Trimethoprim } \\
\text { Kanamycin } \\
\text { Streptomycin } \\
\text { Gentamicin } \\
\text { Tetracycline } \\
\text { Ampicillin } \\
\text { Cephaloridine } \\
\text { Carbenicillin } \\
\text { Chloramphenicol } \\
\text { Nalidixic acid }\end{array}$ & $\begin{array}{c}80 \\
25 \\
8 \cdot 5 \\
38 \\
2 \\
84 \\
65 \\
70 \\
16 \\
21 \\
10\end{array}$ & $\begin{array}{r}75 \\
13 \\
16 \\
40 \\
4 \\
82 \\
55 \\
62 \\
26 \\
20 \\
8\end{array}$ & $\begin{array}{r}54 \\
17 \\
11 \\
34 \\
3 \\
74 \\
69 \\
54 \\
31 \\
23 \\
3\end{array}$ & $\begin{array}{c}12 \\
6 \\
4 \\
6 \\
1 \\
54 \\
27 \\
59 \\
10 \\
10 \cdot 5 \\
7\end{array}$ \\
\hline Total strains & 112 & 90 & 35 & 95 \\
\hline
\end{tabular}

Table 3 Percentage of strains of Acinetobacter anitratus resistant to antimicrobial drugs, 1974-75

\begin{tabular}{|c|c|c|c|c|}
\hline \multirow[t]{3}{*}{ Antimicrobial drug } & \multicolumn{4}{|c|}{ Percentage of resistant strains in: } \\
\hline & \multicolumn{2}{|l|}{1974} & \multicolumn{2}{|l|}{1975} \\
\hline & Jan-Jun & $J u l-D e c$ & Jan-Jun & $J u l-D e c$ \\
\hline $\begin{array}{l}\text { Sulphadiazine } \\
\text { Trimethoprim } \\
\text { Kanamycin } \\
\text { Streptomycin } \\
\text { Gentamicin } \\
\text { Tetracycline } \\
\text { Ampicillin } \\
\text { Cephaloridine } \\
\text { Carbenicillin } \\
\text { Chloramphenicol } \\
\text { Nalidixic acid }\end{array}$ & $\begin{array}{r}89 \\
90 \\
61 \\
89 \\
56 \\
92 \\
87 \\
97 \\
6 \\
96 \\
42\end{array}$ & $\begin{array}{l}92 \\
81 \\
52 \\
95 \cdot 5 \\
49 \\
92 \\
90 \\
98 \\
10 \\
97 \\
44\end{array}$ & $\begin{array}{l}83 \\
57 \\
66 \\
91 \\
57 \\
91 \\
63 \\
97 \\
11 \\
94 \\
40\end{array}$ & $\begin{array}{l}66 \\
19 \cdot 5 \\
5 \\
61 \\
4 \cdot 9 \\
32 \\
71 \\
80 \cdot 5 \\
10 \\
73 \\
56\end{array}$ \\
\hline Total strains & 97 & 88 & 35 & 41 \\
\hline
\end{tabular}

Table 4 Percentage of strains of Proteus spp. resistant to antimicrobial drugs (1974-75)

\begin{tabular}{|c|c|c|c|c|}
\hline \multirow[t]{3}{*}{ Antimicrobial drug } & \multicolumn{4}{|c|}{ Percentage of resistant strains in; } \\
\hline & \multicolumn{2}{|l|}{1974} & \multicolumn{2}{|l|}{1975} \\
\hline & Jan-Jun & Jul-Dec & Jan-Jun & Jul-Dec \\
\hline $\begin{array}{l}\text { Sulphadiazine } \\
\text { Trimethoprim } \\
\text { Kanamycin } \\
\text { Streptomycin } \\
\text { Gentamicin } \\
\text { Tetracycline } \\
\text { Ampicillin } \\
\text { Cephaloridine } \\
\text { Carbenicillin } \\
\text { Chloramphenicol } \\
\text { Nalidixic acid }\end{array}$ & $\begin{array}{r}83 \\
10 \\
9 \\
4 \\
0 \\
95 \\
10 \\
15 \\
5 \\
15 \\
6\end{array}$ & $\begin{array}{c}63 \cdot 5 \\
6 \\
2 \\
8 \\
0 \\
98 \\
8 \\
19 \\
4 \\
6 \\
8\end{array}$ & $\begin{array}{r}45 \\
13 \\
0 \\
2 \\
2 \\
89 \\
15 \\
13 \\
0 \\
6 \\
4\end{array}$ & $\begin{array}{c}58 \cdot 5 \\
21 \cdot 5 \\
0 \\
0 \\
0 \\
72 \\
8 \\
29 \\
6 \\
0 \\
1 \cdot 5\end{array}$ \\
\hline Total strains & 96 & 52 & 47 & 65 \\
\hline
\end{tabular}

carbenicillin. Miscellaneous Enterobacteriaceae showed a progressive reduction in the proportions that were resistant to sulphadiazine, but there was less evidence of an associated fall in resistance to antibiotics. A. anitratus and Proteus sp showed little or no reduction (in the case of Proteus there was a slight increase) in sulphadiazine resistance after the withdrawal of sulphonamides, but $A$. anitratus $\overrightarrow{\vec{s}_{\vec{p}}}$ showed a large reduction in kanamycin, gentamicintrimethoprim, and tetracycline resistance in the second half of 1975 .

A selection of resistant strains of several species, tested by a plate dilution method was found to be highly resistant to sulphadiazine (minimum inhibis tory concentration $>1000 \mu \mathrm{g}$ per $\mathrm{ml}$ ).

\section{Role of plasmids in the rise and fall of resistant Enterobacteriaceae in the Burns Unit}

The fall in the proportion of strains (especially of Klebsiella) resistant to several antibiotics when sulphonamides were withheld suggested that sulphon amides were exerting a selection pressure that favoured strains with linked resistance to these agents. Such linked resistance is often transferablet to sensitive Enterobacteriaceae in mixed culture $\stackrel{D}{D}$ We examined strains of various species of Entero bacteriaceae isolated from burns during the period when sulphadiazine-resistant strains were pre $\overrightarrow{0}$ dominant for transferable resistance patterns.

\section{MATERIAL AND METHODS}

A random selection of strains of $E$. coli, Klebsiella spp, Proteus spp, Enterobacter spp, Citrobactero spp, Serratia spp, and $A$. anitratus isolated in 1974 and 1975 was examined for the transfer of resistance patterns that included sulphadiazine.

Resistance transfer to $E$. coli $\mathrm{K} 12$ was tested with a strain of the recipient that was resistant to strepto mycin or to nalidixic acid, depending on the sensi tivity of the donor strains, growth of which was to be suppressed. One millilitre of 24-hour nutrient brotho cultures of donor and recipient strains was added to $2 \mathrm{ml}$ of nutrient broth, and the mixed culture waś incubated for 24 hours at $37^{\circ} \mathrm{C}$. It was then centri fuged at $3000 \mathrm{rev} / \mathrm{min}$ for 15 minutes, and the deposit was resuspended in $0.2 \mathrm{ml}$ of nutrient broth, which was plated on nutrient agar containing $200 \mu \mathrm{g}$ per ml sodium sulphadiazine and $200 \mu \mathrm{g}$ per $\mathrm{ml}$ nalidixic acid or streptomycin; the plates were incubated at $37^{\circ} \mathrm{C}$ for 24 hours, after which colonies were picked, identified as $E$. coli by con $N$ firmatory biochemical tests, and tested for sensitivityb to sulphadiazine, trimethoprim, kanamycin, gentamicin, streptomycin, ampicillin, cephaloridine $\frac{-}{\mathrm{D}}$ carbenicillin, tetracycline, chloramphenicol, and? nalidixic acid by a ditch plate method (see above).

RESULTS

Table 5 shows the patterns of resistance transferred 
Table 5 Transferable resistance patterns including sulphadiazine in Gram-negative bacilli isolated from burns

\begin{tabular}{llll}
\hline Bacteria from burns & $\begin{array}{l}\text { Number of } \\
\text { strains } \\
\text { tested }\end{array}$ & $\begin{array}{l}\text { Number which } \\
\text { transferred } \\
\text { resistance }\end{array}$ & Resistance patterns transferred (and number of strains) \\
\hline E. coli & 15 & 4 & K A Ca S (1), A Ca S (1), T S (1), T Cl A Ca S (1) \\
Enterobacter sp & 11 & 5 & T S (1), St S (3), S (1) \\
Citrobacter sp & 3 & 1 & T K S (1) \\
Serratia sp & 8 & 1 & St Ce K A Ca S (1) \\
Klebsiella sp & 22 & 14 & K A Ca S (2), T Ce Cl A Ca S (4), Ce Cl A Ca S (2), T S (1), S (2), T Cl A Ca S (3) \\
$\begin{array}{ll}\text { Acinetobacter anitratus } \\
\text { Proteus sp }\end{array}$ & 20 & 0 & -
\end{tabular}

$\mathrm{T}=$ tetracycline; $\mathrm{K}=$ kanamycin $; \mathrm{Ca}=$ carbenicillin; $\mathrm{St}=$ streptomycin; $\mathrm{A}=$ ampicillin; $\mathrm{S}=$ sulphadiazine $; \mathrm{Ce}=$ cephaloridine; $\mathrm{Cl}=$ chloramphenicol

Table $6^{1}$ Elimination of transferable resistance patterns on withdrawal of sulphonamide

\begin{tabular}{lll}
\hline Year & $\begin{array}{l}\text { \% Strains of Klebsiella sp showing resistance } \\
\text { patterns } \mathrm{TCe} C \mathrm{Cl} \text { Ca S, T Cl A Ca S, and } \\
\text { Ce Cl A Ca S }\end{array}$ & $\begin{array}{l}\text { Number of } \\
\text { strains } \\
\text { tested }\end{array}$ \\
\hline 1972 & 14 & 44 \\
1973 & 23 & 48 \\
1974 & & 71 \\
Jan-Jun & 66 & 34 \\
$\begin{array}{l}1974 \\
\text { Jul-Dec }\end{array}$ & 38 & 24 \\
$\begin{array}{l}\text { 1975 } \\
\text { Jan-Jun }\end{array}$ & 79 & 15 \\
1975 & & \\
Jul-Dec & 0 & \\
\hline
\end{tabular}

'See footnote to Table 5

to $E$. coli $\mathrm{K} 12$ by strains of Gram-negative bacilli from burns that were tested. Fourteen of the 22 strains of Klebsiella sp transferred resistance to the recipient strain, in contrast with no transfer of resistance from 20 strains of $A$. anitratus and from 12 strains of Proteus spp. The commonest pattern transferred by Klebsiella sp (4 strains) was tetracycline, cephaloridine, chloramphenicol, ampicillin, carbenicillin, and sulphadiazine (T $\mathrm{Ce} \mathrm{Cl} \mathrm{A} \mathrm{Ca} \mathrm{S}$ ), but five strains transferred the closely related pattern $\mathrm{Ce} \mathrm{Cl} \mathrm{A} \mathrm{Ca} \mathrm{S} \mathrm{(2)} \mathrm{and} \mathrm{T} \mathrm{Cl} \mathrm{A} \mathrm{Ca} \mathrm{S} \mathrm{(3).}$

The transfer of resistance plasmids from Enterobacter sp, Serratia sp, E. coli, and Citrobacter sp was also demonstrated.

Table 6 shows the proportion of isolates of Klebsiella sp from burns in the years 1972 to 1975 which showed the resistance patterns $\mathrm{T} \mathrm{Ce} \mathrm{Cl} \mathrm{A} \mathrm{Ca} \mathrm{S}$, $\mathrm{T} \mathrm{Cl} \mathrm{A} \mathrm{Ca} \mathrm{S}$, and $\mathrm{Ce} \mathrm{Cl} \mathrm{A} \mathrm{Ca} \mathrm{S}$. The frequency of isolation of strains showing these patterns rose from a low level in 1972 to a very high level in 1974 and in the first half of 1975, ie, during the period when sulphadiazine resistance had become predominant; in the six months after the withdrawal of sulphonamides and silver sulphadiazine from the Burns Unit, strains of Klebsiella sp showing these resistance patterns (the related patterns most commonly transferred by $\mathbf{R}$ factors) were no longer found in $\mathbf{a}$ series of strains tested. In the same period Klebsiella isolations became less common (for example, in the year 1974 there were 599 isolations of Klebsiella and in January to June 1975 there were 270 isolations, but only 59 isolations were recorded in July to December 1975). There had been an increase in isolations of Klebsiella strains resistant to chloramphenicol, tetracycline, cephaloridine, and ampicillin associated with the increase in sulphadiazine resistance during the period 1972-74 (see Table 7), but this increase was smaller than the fall which followed the withdrawal of sulphonamide treatment in June 1975.

Table 7 Resistance of Klebsiella sp 1972-75

\begin{tabular}{|c|c|c|c|c|c|c|c|}
\hline \multirow[t]{2}{*}{ Year } & \multicolumn{6}{|c|}{$\begin{array}{l}\text { Percentage of strains of Klebsiella } \\
\text { resistant to }\end{array}$} & \multirow{2}{*}{$\begin{array}{l}\text { Total } \\
\text { number } \\
\text { strains } \\
\text { tested }\end{array}$} \\
\hline & $T^{1}$ & $\mathrm{Ce}$ & $\mathrm{Cl}$ & $A$ & $\mathrm{Ca}$ & $S$ & \\
\hline 1972 & 64 & 36 & 18 & 66 & 91 & 32 & 44 \\
\hline 1973 & 48 & 56 & 35 & 77 & 69 & 56 & 48 \\
\hline 1974 Jan-Jun & 90 & 63 & 84 & 89 & 86 & 94 & 71 \\
\hline $1974 \mathrm{Jul}-\mathrm{Dec}$ & 94 & 59 & 53 & 68 & 71 & 88 & 34 \\
\hline 1975 Jan-Jun & 96 & 87 & 87 & 87 & 87 & 92 & 24 \\
\hline 1975 Jul-Dec & 20 & 33 & 0 & 20 & 33 & 20 & 15 \\
\hline
\end{tabular}

${ }^{1}$ See footnote to Table 5

\section{Discussion}

The fall in sulphonamide, trimethoprim, and antibiotic resistance of Klebsiella after the withdrawal of sulphonamide treatment in the Burns Unit was associated with the disappearance from the Unit of Klebsiella strains with linked patterns of resistance to tetracycline, cephaloridine, chloramphenicol, ampicillin, carbenicillin, and sulphadiazine ( $\mathrm{T} \mathrm{Ce} \mathrm{Cl}$ $\mathrm{A} \mathrm{Ca} \mathrm{S),} \mathrm{and} \mathrm{to} \mathrm{closely} \mathrm{related} \mathrm{patterns} \mathrm{of} \mathrm{resistance}$ ( $\mathrm{T} \mathrm{Cl} \mathrm{A} \mathrm{Ca} \mathrm{S}$ and $\mathrm{Ce} \mathrm{Cl} \mathrm{A} \mathrm{Ca} \mathrm{S}$ ); these patterns were transferred to $E$. coli $\mathrm{K} 12$ in conjugation experiments. Their apparent elimination from the Unit was associated with a reduced incidence of Klebsiella infection of burns, a result reminiscent of that reported by Price and Sleigh (1970) in a neurosurgery ward where giving up the routine prophylactic use of streptomycin and ampicillin led to a great reduction 
in the incidence of Klebsiella infections. Unlike the $\mathbf{R}$ factor $\mathbf{R P}_{\mathbf{1}}$, which was not removed from Pseudomonas aeruginosa and Enterobacteria in this Unit until all five antibiotics to which it determined resistance were withdrawn (Lowbury et al., 1972; Roe and Lowbury, 1972), the $\mathrm{R}$ factor determining the resistance T $\mathrm{Ce} \mathrm{Cl} \mathrm{A} \mathrm{Ca} \mathrm{S,} \mathrm{T} \mathrm{Cl} \mathrm{A} \mathrm{Ca} \mathrm{S}$ and $\mathrm{Ce} \mathrm{Cl} \mathrm{A} \mathrm{Ca} \mathrm{S}$ in Klebsiella spp was removed from the Unit by discontinuing the use of only one group of antimicrobials represented in the patterns (the sulphonamides).

The patterns of resistance and the response to the removal of selection pressure exerted by sulphonamide therapy were complex. Several different patterns of resistance were transferred by Klebsiella and Enterobacter sp. Proteus did not show the presence of $\mathbf{R}$ factors in the strains tested, and there was little or no change in the proportions of Proteus resistant to sulphadiazine, trimethoprim or the antibiotics on withdrawal of the sulphonamides from the Unit; but $A$. anitratus, which also showed no transfer of resistance to $E$. coli $\mathrm{K} 12$, appeared to respond to the withdrawal of sulphonamides in the ward by a large reduction in the proportions of strains resistant to trimethoprim, tetracycline, gentamicin, and kanamycin. But this association was probably coincidental and due to factors other than the withdrawal of sulphonamides, for there was little reduction in the proportion of sulphadiazine-resistant $A$. anitratus at the time when gentamicin, kanamycin, trimethoprim, and tetracycline resistance fell sharply. A large reduction in the proportions of Klebsiella resistant to trimethoprim, kanamycin, streptomycin, and gentamicin occurred in the six months immediately before the withdrawal of sulphonamides and was clearly due to factors other than sulphonamide usage.

\section{References}

Cason, J. S., Jackson, D. M., Lowbury, E. J. L., and Ricketts, C. R. (1966). Antiseptic and aseptic prophylaxis for burns: use of silver nitrate and of isolators. British Medical Journal, 2, 1288-1294.
Cason, J. S. and Lowbury, E. J. L. (1960). Prophylactio chemotherapy for burns: studies on local and systemie use of combined therapy. Lancet, 2, 501-507.

Cowan, S. T. and Steel, K. J. (1965). Manual for thet Identification of Medical Bacteria. Cambridge Uni? versity Press, Cambridge.

Fox, C. L., Jr., Rappole, B. W., and Stanford, W. (1969)을 Control of pseudomonas infection in burns by silvef sulfadiazine. Surgery, Gynecology and Obstetrics, 128 1021-1026.

Hummel, R. P., MacMillan, B. G., and Altemeier, W. A\% (1970). Topical and systemic antibacterial agents ino the treatment of burns. Annals of Surgery, 172, 370-384 Jackson, D. M., Lowbury, E. J. L., and Topley, E. (1951) Pseudomonas pyocyanea in burns: its rôle as a patho gen, and the value of local polymyxin therapy. Lancet? 2, 137-147.

Lowbury, E. J. L., Babb, J. R., Bridges, K., and Jackson D. M. (1976). Topical chemoprophylaxis with silvet sulphadiazine and silver nitrate chlorhexidine creams? emergence of sulphonamide-resistant Gram-negatives bacilli. British Medical Journal, 1, 493-496.

Lowbury, E. J. L., Babb, J. R., and Roe, E. (1972) $\vec{T}$ Clearance from a hospital of Gram-negative bacilli that transfer carbenicillin-resistance to Pseudomonas? Lancet, 2, 941-945.

Lowbury, E. J. L., Jackson, D. M., Lilly, H. A., Bul1, J. P., Cason, J. S., Davies, J. W. L., and Ford, P. M $\overrightarrow{6}$ (1971a). Alternative forms of local treatment for buress Lancet, 2, 1105-1111.

Lowbury, E. J. L., Jackson, D. M., Ricketts, C. R., Davis, B. (1971b). Topical chemoprophylaxis burns: trials of creams containing silver sulphadiazineo and trimethoprim. Injury, 3, 18-24.

Price, D. J. E. and Sleigh, J. D. (1970). Control of infection due to Klebsiella aerogenes in a neurosurgica unit by withdrawal of all antibiotics. Lancet, 2, 1213윽 1215.

Roe, E. and Lowbury, E. J. L. (1972). Changes in anti biotic sensitivity patterns of Gram-negative bacilli in. burns. Journal of Clinical Pathology, 25, 176-178.

Stanford, W., Rappole, B. W., and Fox, C. L., Jr. (1969) Clinical experience with silver sulphadiazine, a news topical agent for control of pseudomonas infections of burns. Journal of Trauma, 9, 377-388.

Topley, E., Lowbury, E. J. L., and Hurst, L. (1951)? Bacteriological control of aureomycin therapy. Lancet? 1, 87-89. 